\title{
MacArthur Stem Story Battery: Narrativas Infantis como Acesso às Representações Mentais
}

\author{
Joana Alvares, Letícia Fagundes Machado, Silvia Pereira da Cruz Benetti \\ Universidade do Vale do Rio dos Sinos ${ }^{1}$, São Leopoldo-RS, Brasil
}

\section{RESUMO}

Este trabalho teve por objetivo identificar e comparar as representações mentais de crianças maltratadas e não maltratadas com base nas narrativas do MSSB, e avaliar as propriedades psicométricas iniciais de tal instrumento. Participaram 90 crianças em idade escolar de 6-10 anos de idade $(M=8,0)$, sendo 30 vítimas de maus-tratos e 60 não vítimas. Os instrumentos utilizados foram o SDQ e MSSB. As representações mentais das crianças maltratadas foram retratadas como mais negativas, se comparadas às não maltratadas, com teores de cunho mais agressivo, indicando baixa regulação emocional e impulsividade frente a situações conflitantes e, figuras de cuidado mais inseguras e ineficazes. Evidencia-se, ainda, que alguns itens do MSSB são capazes de discriminar os grupos de forma significativa, além deste apresentar bons índices de confiabilidade. Evidencia-se as narrativas como útil recurso de avaliação e planejamento de intervenções terapêuticas com essas crianças. Desenvolvimento de novos estudos nacionais a fim de aprimorar técnicas validas e para compreender as representações no âmbito da violência infantil.

Palavras-chave: representação mental, maus-tratos, narrativas infantis.

\section{ABSTRACT - MacArthur Stem Story Battery: Child Narratives as Access to Mental Representations}

The objective of this study was to identify and compare the mental representations of abused and non-abused children based on MSSB narratives, and to evaluate the initial psychometric properties of such instrument. Ninety school age children, from 6-10 years old $(M=8.0)$, participated in the study, of which 30 were victims of mistreatment and 60 were non-victims. The instruments used were the SDQ and MSSB. Mental representations of abused children were portrayed as more negative when compared to non-abused ones, with more aggressive characteristics indicating low emotional regulation and impulsivity in the face of conflicting situations, and more insecure and ineffective care figures. Some items of the MSSB also evidenced an ability to discriminate the groups in a significant way, in addition to presenting good reliability indices. The narratives are shown as a useful resource for the evaluation and planning of therapeutic interventions with these children. Development of new national studies is recommended in order to improve valid techniques and to understand representations in the field of child violence.

Keywords: mental representation, maltreatment, children's narratives.

RESUMEN - MacArthur Stem Story Battery: Narrativas de los Niños como el Acceso a las Representaciones Mentales

Este trabajo tuvo por objetivo identificar y comparar las representaciones mentales de niños maltratados y no maltratados basados en relatos del MSSB, y evaluar las propiedades psicométricas iniciales de tal instrumento. Participaron 90 niños en edad escolar de 6-10 años de edad $(M=8.0)$, siendo 30 víctimas de maltrato y 60 no maltratados. Los instrumentos utilizados fueron el SDQ y MSSB. Las representaciones mentales de niños maltratados fueron descriptas como más negativas, en comparación con los no maltratados, con un contenido de corte más agresivo, indicando baja regulación emocional e impulsividad frente a situaciones conflictivas y figuras de cuidado más inseguras e ineficaces. También muestra que algunos ítems del MSSB son capaces de discriminar los grupos de forma significativa, además de presentar buenos índices de confiabilidad. Se evidencian las narrativas como útiles recursos de evaluación y planeamiento de intervenciones terapéuticas con esos niños. Se deben desarrollar nuevos estudios nacionales con el fin de mejorar técnicas válidas y comprender las representaciones en el ámbito de violencia infantil.

Palabras clave: representación mental, maltratos, narrativas infantiles.

\section{Introdução}

Ao longo do desenvolvimento, a criança constrói representações de si mesma e dos demais que influenciam como ela se percebe no mundo e o modo que se relaciona com as pessoas em seu contexto. Essas representações mentais do self e do outro derivam das experiências com as figuras cuidadoras, principalmente das interações no ambiente familiar, e baseiam a forma como a criança interpreta a realidade vivida e interage com ela, isso porque essas representações mentais trabalham como um mapa interno, que possibilita à criança a antecipação das 
respostas dos outros, que utiliza essa informação para guiar o seu comportamento, tanto no contexto familiar, como também nos diversos contextos sociais em que está inserida (Custódio \& Cruz, 2008).

De acordo com Priel, Besser, Waniel, Yonas-Segalm e Kuperminc (2007), o construto Representação Mental está associado a conceitos pertencentes tanto à Teoria do Apego quanto à Teoria das Relações Objetais. Dessa forma, as representações de si, do outro e do ambiente derivam das experiências reais interpessoais e dos aspectos intrapsíquicos ligados à dinâmica do mundo interno infantil (Mesquita \& Benetti, 2014). Nesse sentido, as representações mentais constituem um importante fator mediador das experiências infantis e permitem conhecer e avaliar, por meio do seu acesso, as implicações existentes no contexto do desenvolvimento global da criança (Mendes \& Sani, 2015).

Com base no interesse em identificar o aspecto representacional constituído pelas crianças em distintos contextos de desenvolvimento, diversos estudos (Toth, Cicchetti, Macfie, Maughan, \& VanMeenen, 2000; Emde, Wolf, \& Oppenheim, 2003; Custódio \& Cruz, 2008; Benavente, Justo, \& Verissimo, 2009; Hawkins \& Haskett, 2013; Mesquista \& Benetti, 2014; Mendes \& Sani, 2015) foram realizados voltados para a identificação das representações infantis, como também para o impacto de situações de risco e vulnerabilidade nas trajetórias de desenvolvimento. Para tal, instrumentos dirigidos para a identificação das representações mentais da criança e das figuras cuidadoras, bem como das características da interação entre eles foram, desenvolvidos.

Um dos instrumentos com base nesses pressupostos é o MacArthur Story Stem Battery (MSSB, Emde, Wolf, \& Oppenheim, 2003). Trata-se de um método que utiliza narrativas para investigar áreas que abrangem tanto o desenvolvimento moral quanto a expressividade emocional, o comportamento pró-social, a representação parental, os mecanismos defensivos, a regulação emocional (Langevin, Cossette, \& Hebert, 2016) e as estratégias de resolução de conflitos (Emde et. al., 2003), abrangendo assim toda a compreensão acerca do construto Representação Mental Infantil. As narrativas constituem-se de histórias-tronco, que apresentam à criança situações de dilemas morais ou de conflito, que deve continuar a narrativa visando à solução/encaminhamento da situação problema. Por essas características, as narrativas evocam o sistema representacional da criança, tanto de seu mundo social quanto de aspectos intrapsíquicos (Holmberg, Robinson, Corbitt-Price, \& Wiener, 2007).

Dessa maneira, os instrumentos narrativos se apresentam como uma ferramenta útil para avaliação das representações infantis, já que técnicas projetivas, como o ato de narrar, permitem uma avaliação mais compreensiva das representações mentais em vários níveis (Robinson, Mantz-Simmons, MacFie, Kelsay, \& Homberg, 2007). Assim, o modo como a criança retrata seus personagens nas narrativas está associado às suas experiências e relacionamentos interpessoais (Oppenheim, Nir, Warren, \& Emde, 1997), pois ela atribui significados para essas mesmas experiências e as integra nas suas histórias de vida (Fivush, Hazzard, Sales, Sarfati, \& Brown, 2003; Mendes \& Sani, 2015). A narrativa surge, então, como um veículo essencial para o conhecimento das construções subjetivas da criança acerca das suas experiências e interações (Emde, 2003).

A técnica narrativa do MSSB iniciou-se com base no trabalho do grupo de pesquisa organizado por Bretherton, Emde, Openheimn e Wolf, os quais se alicerçaram no trabalho já realizado com o Attachment Story Completion Task (ASCT, Bretherton, Ridgeway, \& Cassidy, 1990), que avalia o apego, e introduziram novas lâminas com temáticas relacionais e pró-sociais. Inicialmente, a técnica consistia em 30 narrativas, que são inícios de histórias, chamadas de histórias-tronco. Porém, atualmente, trabalha-se com um total de 14 inícios narrativos, sendo que duas não são avaliadas e têm a função de introduzir e finalizar a aplicação do instrumento. Embora se tenha elaborado 14 histórias, estas podem ser aplicadas a partir do tema que se quer estudar, entretanto, neste estudo, todas as 14 histórias-troco foram utilizadas. Além disso, durante a aplicação, o entrevistador faz uso de uma família de bonecas para que as crianças desenvolvam e finalizem as histórias (Hodges, Steele, Hillman, \& Henderson, 2003). Trabalhos investigativos, utilizando-se do MSSB, têm-se valido de abordagens oriundas de aportes psicanalíticos e da Teoria do Apego, socioconstrutivistas, que resultaram em informações importantes sobre as representações de cuidado e proteção parental, e os mecanismos defensivos das crianças frente ao conflito nas relações familiares (Holmberg et al., 2007).

O instrumento MSSB tem sido amplamente utilizado na investigação das representações mentais ou modelos internos do vínculo com as figuras parentais, isso porque permite capturar a continuidade das reações das crianças por meio de histórias, quando lhes é apresentado um dilema para resolução que irá revelar alguns aspectos de seu mundo interno (Emde, Wolf, \& Oppenheim, 2003). Dessa maneira, a técnica narrativa das histórias-troncos permite ser aplicada em diversas áreas do desenvolvimento infantil e da saúde mental, verificando as características infantis e as representações acerca da sua família e de seu contexto de relacionamentos (Franieck, Günter, \& Page, 2014).

Investigações comparativas entre crianças maltratadas e não maltratadas assinalam diferenças significativas, no que se refere às representações de si e das figuras de cuidado. Waldinger, Toth e Gerber (2001), em uma pesquisa com crianças americanas de cinco anos, utilizando as histórias-tronco do MSSB, concluíram que crianças, as quais sofreram maus-tratos, demonstram, com maior frequência, imagens negativas de si quando comparadas às crianças não maltratadas. 
Benavente, Justo e Veríssimo (2009), em uma investigação com 60 crianças portuguesas em idade pré-escolar, verificaram que as vivências de maus-tratos estão ligadas a representações inseguras de vínculo, não havendo diferenças significativas entre gênero e tipo de maus-tratos sofridos. Em outro estudo desenvolvido em Portugal, no âmbito das representações parentais, Sousa e Cruz (2010) analisaram o modo como às experiências dos maus-tratos estão associadas ao processo de construção dos modelos representacionais de 22 crianças acolhidas institucionalmente comparadas com crianças não acolhidas. As primeiras representavam as figuras de cuidado como menos sensíveis e responsivas às suas necessidades e desejos, além de serem caracterizadas como mais punitivas em situações de conflito.

Ao examinar as representações parentais, Stronach et al. (2011), investigaram 92 crianças americanas em idade pré-escolar vítimas de maus-tratos e 31 crianças sem experiências maltratantes. A avaliação das narrativas do MSSB permitiu identificar que as crianças vítimas de maus-tratos tiveram menores índices de apego seguro e maiores índices de apego desorganizado do que crianças não maltratadas. As representações parentais identificaram figuras negativas e as representações de si, das crianças, associavam-se a imagens grandiosas e poderosas de si mesmas.

Observa-se, portanto, que a compreensão e a constituição das representações mentais infantis podem contribuir para ampliar o entendimento da forma que essas representações se desenvolvem e qual o impacto que as experiências de maus-tratos causam no psicológico infantil. Algumas hipóteses sobre como as crianças representam, nas narrativas, a qualidade das interações dos cuidadores, indicam que os personagens podem refletir as vivências e experiências das crianças de conflito no seu contexto. Essa situação sustentaria a hipótese representacional das narrativas, indicando que os personagens revivem aspectos da experiência infantil. Por outro lado, a hipótese da regulação emocional indica que as crianças evitam retratar determinados comportamentos dos personagens nas suas narrativas para não se confrontarem com as emoções negativas que determinadas narrativas ocasionam (Clyman, 2003). Com base nessas questões, verifica-se a necessidade e o aprimoramento de novos estudos e técnicas que visem a compreender e acessar tais representações. Portanto, esta pesquisa objetiva: a) identificar as representações mentais das crianças vítimas e não vítimas de maus-tratos, com base nas narrativas do MSSB e, b) avaliar as propriedades psicométricas iniciais do instrumento MSSB.

\section{Método}

\section{Delineamento}

Estudo quantitativo, de caráter correlacional e exploratório (Sampieri, Collado, \& Lucio, 2013).

\section{Amostra}

Participaram deste estudo 90 crianças em idade escolar (6-10 anos de idade), sendo 30 delas em situação de acolhimento institucional, por motivo de maus-tratos e provenientes de Casas de Acolhimento Institucional da Região Metropolitana de Porto Alegre e da Serra, além de 60 crianças provenientes da rede municipal/estadual de ensino das mesmas regiões. Os participantes foram selecionados por conveniência pelas instituições e, posteriormente, triados para participar do estudo.

\section{Instrumentos}

MacArthur Story Stem Battery (MSSB - Emde et al., 2003). Trata-se de um método que utiliza 14 narrativas para estudar áreas que abrangem o desenvolvimento moral, quanto à expressividade emocional, ao comportamento pró-social, à representação parental, à agressividade, ao controle, ao temperamento, à natureza dos processos defensivos, à regulação emocional e estratégias de resolução de conflitos. Em contato pessoal com um dos autores do instrumento, foi obtido o consentimento para o uso das narrativas, bem como obtido o manual de correção Manual de Codificação do MSSB de Robinson et al. (2007). O Manual de Codificação do MSSB apresenta seis categorias de avaliação das narrativas: o conteúdo dos temas: conflitos interpessoais, da relação empática, de agressão e de temas morais; os códigos emocionais: temas de perigo, segurança, destruição de objetos, o poder da criança, reação a separação, incoerência emocional, a primeira reação e o conteúdo final; as representações parentais: triangulação, disciplina e controle, representação positiva (protetor, afetuoso, cuidador e ajuda) e representação negativa (punitivas, rejeição e ineficaz); os códigos de performance: controle, a raiva, a alegria, a angústia, o interesse, a tristeza, coerência narrativa e estilo de performance; as estratégias de evitação: a exclusão, repetição, negação e ruptura familiar; e os códigos de dissociação: fuga de assunto doloroso, identificação com agressor, propensão à fantasia, distração, absorção e material traumático Os itens são avaliados em presentes (1) e ausentes (0) e outros avaliados de 0 a 10 , conforme a intensidade apresentada nas narrativas infantis. No presente estudo, optou-se por uma codificação padronizada, avaliando somente a presença (1) ou ausência (0) dos itens, conforme utilizado por Toth et al. (2000) e Waldinger et al. (2001). Na aplicação do instrumento, utiliza-se a Família Terapêutica, com o intuito de facilitar a expressão e projeção da criança nos bonecos ao narrar às histórias.

Questionário de Capacidades e Dificuldades (Versão Pais - Professores - SDQ - Fleitlich, Cartázar e Goodman, 2000). Trata-se de um questionário de triagem comportamental de crianças e adolescentes de 3 a 16 anos de idade. É composto por 25 itens que 
concentram cinco escalas de investigação: problemas no comportamento pró-social, hiperatividade, problemas emocionais, de conduta e de relacionamento. Essas escalas são pontuadas de 0 a 2 , sendo que 0 é falso, 1 é mais ou menos verdadeiro e 2 é verdadeiro. A pontuação total é gerada a partir da soma das escalas, exceto a de sociabilidade.

\section{Procedimentos de Coleta de Dados}

Inicialmente o contato com as instituições participantes da pesquisa foi realizado, sendo estas uma Casa de Acolhimento e uma Escola Estadual e/ou Municipal, ambas na Região Metropolitana de Porto Alegre e outra na Região da Serra. A partir do aceite de participação, a amostra foi selecionada por conveniência.

$\mathrm{Na}$ escola, a coleta dos dados foi realizada com as turmas de $1^{\circ}$ a $4^{\circ}$ ano. Os professores foram contatados, visando a uma seleção e indicação prévia de crianças, avaliadas como tendo um desenvolvimento adequado à idade e bom relacionamento familiar. A partir disso, foi enviada aos pais a Carta de Apresentação do estudo, o Termo de Consentimento Livre e Esclarecido (TCLE) e o SDQ. Salienta-se que as crianças que, a partir do preenchimento do questionário, apresentaram escores indicativos de anormalidade foram excluídas do estudo e encaminhadas para atendimento. A aplicação se deu de forma individual e em local e horário adequado, com duração de 45 minutos a 1 hora, sendo realizada pela psicóloga, autora do estudo, e por alunos colaboradores do projeto.

Nas Casas de Acolhimento, a partir de uma reunião com a coordenação e com os educadores da instituição para explicação do projeto, entrega e assinatura do Termo de Consentimento Livre e Esclarecido (TCLE), a seleção e indicação de crianças com casos de maus-tratos foi realizada, e o questionário SDQ foi dividido entre a equipe para ser preenchido. Após isso, foi realizada uma análise nos prontuários das crianças e a aplicação do instrumento foi realizada de forma individual, em sala e horário adequados para o trabalho.

Todas as aplicações em ambas às instituições foram gravadas em áudio e, quando finalizadas, os pesquisadores registravam as principais características do comportamento das crianças durante a elaboração das narrativas e se reuniam para avaliação destas. Neste estudo, priorizou-se o bem-estar da criança na aplicação do instrumento, e reuniões de discussão de casos e resultados foram realizadas com as instituições para encaminhamento de casos com necessidade de avaliação mais ampla, bem como para buscar uma compreensão e qualificação maior de manejo das equipes para com as crianças acolhidas. A presente pesquisa foi submetida ao Comitê de Ética em Pesquisa da Universidade do Vale do Rio dos Sinos - UNISINOS, e respeitou a Resolução 510/16 do Conselho Nacional de Saúde e CFP 010/2012, que preconiza a pesquisa com seres humanos, além de assegurar a proteção e integridade das crianças participantes.

\section{Procedimentos de Análise de Dados}

Os resultados foram organizados sob a forma de estatística descritiva, sendo as variáveis categóricas por meio de distribuições absoluta e relativa, e as variáveis contínuas por média, desvio padrão, mediana e amplitude. A distribuição de normalidade foi verificada a partir do teste de Kolmogorov Smirnov. A comparação das variáveis contínuas, entre os grupos maltratados e não maltratados, ocorreu pelos testes $t$ Student e teste de Mann Whitney e, quando as comparações ocorreram sobre variáveis categóricas, foram utilizados os testes Qui-Quadrado de Pearson e Exato de Fisher.

A análise de confiabilidade foi investigada pela técnica alfa de Cronbach, que estuda a congruência que cada item do teste apresenta com relação ao restante dos itens. A fidedignidade do instrumento se refere à propriedade de ser consistente e de medir com menor número de erros (Pasquali, 2003). Paras tais critérios de decisão estatística, adotou-se o nível mínimo de significância de 5\%.

Os dados foram analisados por meio do programa Statistical Package for Social Sciences versão 20.0 (SPSS Inc., Chicago, IL, USA, 2010) para Windows.

\section{Resultados}

Para a análise da confiabilidade interna do instrumento MSSB, foi calculado o alfa de Cronbach, obtendo-se confiabilidade alta nas dimensões de Agressão Desregulada $(\alpha=0,85)$ e Representação Parental - Positiva $(\alpha=0,85)$; com confiabilidade moderada nas dimensões Conflitos Interpessoais $(\alpha=0,64)$, Representação Parental - Negativas $(\alpha=0,695)$ e nos Códigos de Dissociação $(\alpha=0,67)$. Com confiabilidades baixa e muito baixa, destacaram-se as dimensões Relação Empática $(\alpha=0,24)$, Códigos Emocionais das Narrativas $(\alpha=0,30)$ e Temas Morais $(\alpha=0,27)$, apontando para um comprometimento da consistência interna sobre os fatores citados, o que se deve, em parte, ao número reduzido de itens por dimensão aliado ao tamanho amostral do estudo (Ryff \& Keyes, 1995).

De acordo com a Tabela 1, verifica-se que tanto a variável Sexo quanto Idade foram equivalentes entre os grupos. Quanto à série escolar, prevaleceram crianças no $2^{\mathrm{a}}$ ano do ensino fundamental no grupo não maltratado $(53,3 \%, n=32)$, enquanto, no grupo maltratado, as informações nos prontuários das casas de acolhimentos não eram precisas com relação à seriação escolar.

Com relação à classificação do instrumento SQD, observou-se que, entre as crianças vítimas de maus-tratos, 46,7\% $(n=14)$ tiveram classificações limítrofe, e $53,3 \%(n=16)$ anormal. 
Tabela 1

Distribuição Absoluta e Relativa para Sexo, Série e SQD, Média e Desvio Padrão para Idade por Grupo

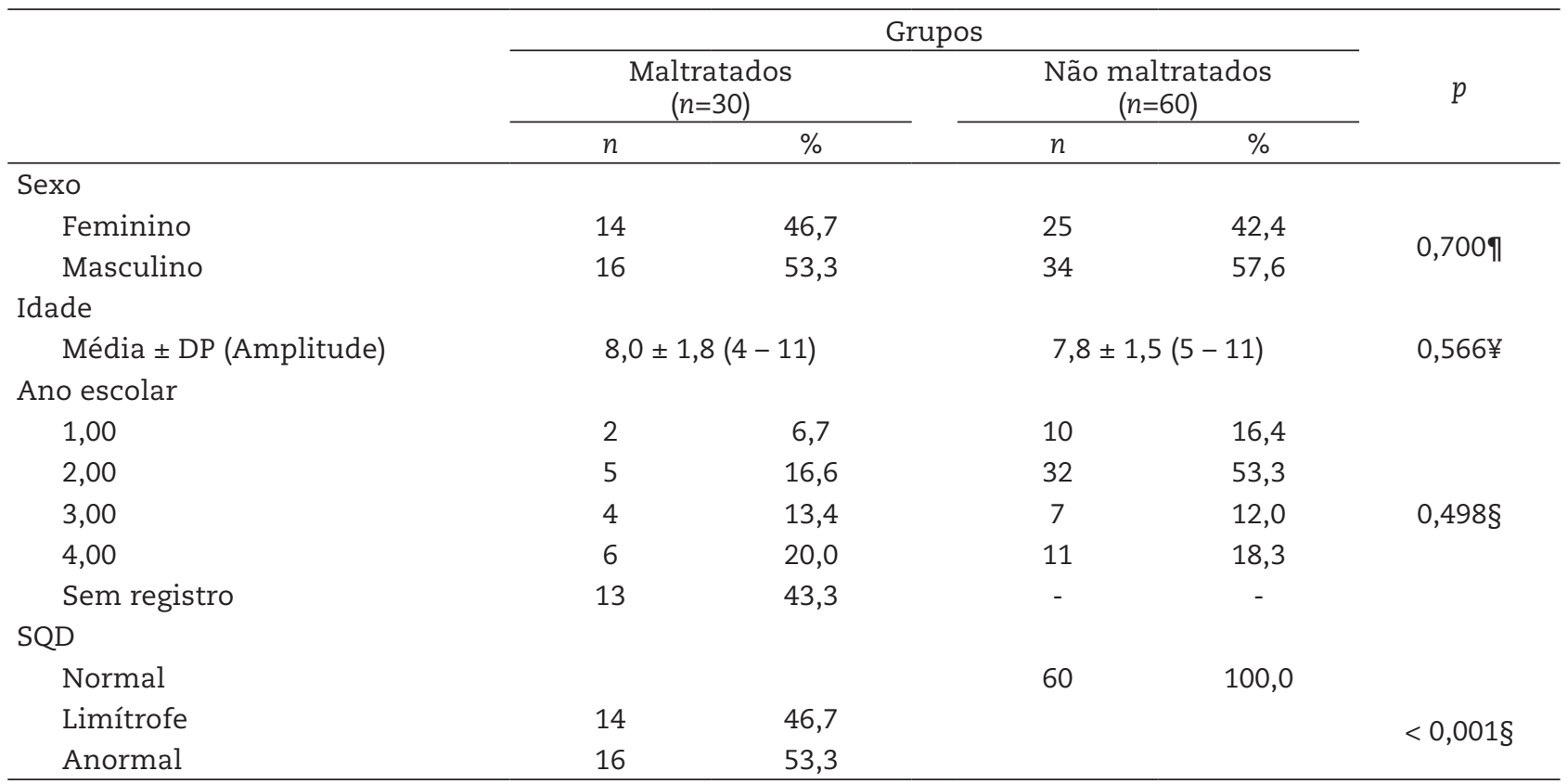

Nota. Teste Qui-quadrado de Pearson; ¥: Teste t-Student para grupos independentes; §: Teste Exato de Fisher

Para efeito de diferenças significativas dos escores dos itens, utilizou-se os testes não paramétricos de Mann-Whitney. De acordo com os resultados da Tabela 2 , as crianças vítimas de maus-tratos apresentaram média significativamente maior em várias dimensões. $\mathrm{Na}$ dimensão Conflito Interpessoal, houve escores mais altos para Competição e Rivalidade/Ciúmes. Em Agressão Desregulada, maiores médias ocorreram para os itens Agressão, Agravamento do Conflito Interpessoal, Resposta Atípicas e Atividade/Agressão Sexualizada. Nos Códigos Emocionais das Narrativas, as diferenças ocorreram para Tema de Perigo, Destruição de Objetos e
Poder da Criança. Na Representação Parental, as médias no grupo G1 foram inferiores nas características positivas (Protetor, Afetuoso, Cuidador e Ajuda) e superiores nas negativas (Punitiva, Rejeição e Ineficaz). Nas dimensões de defesa, ocorreram maiores médias nas Estratégia de Esquiva, Negação, Sono Repentino e Objetivos bloqueados. Por fim, na dimensão Código de Dissociação, diferenças foram encontradas para Material Traumático Invasivo, Fuga de Assunto Doloroso e Identificação com o Agressor. Em suma, diferenças foram observadas para diversas das variáveis da bateria, ocorrendo em um padrão consistente com as expectativas teóricas.

Tabela 2

Média, Desvio Padrão e Mediana para os Itens do MSSB por Grupo

\begin{tabular}{|c|c|c|c|c|c|c|c|}
\hline \multirow{3}{*}{$\begin{array}{l}\text { MSSB } \\
\text { Itens }\end{array}$} & \multicolumn{7}{|c|}{ Grupos } \\
\hline & \multicolumn{3}{|c|}{ Maltratados $(n=30)$} & \multicolumn{3}{|c|}{ Não maltratados $(n=60)$} & \multirow[b]{2}{*}{$p$} \\
\hline & Média & $\mathrm{DP}$ & Mediana & Média & $\mathrm{DP}$ & Mediana & \\
\hline \multicolumn{8}{|c|}{ Categoria: Conteúdo dos Temas } \\
\hline \multicolumn{8}{|c|}{ Conflito Interpessoal } \\
\hline Competição & 0,90 & 1,21 & 0,50 & 0,37 & 0,84 & 0,00 & 0,010 \\
\hline Rivalidade/Ciúmes & 0,83 & 1,32 & 0,00 & 0,33 & 0,93 & 0,00 & 0,013 \\
\hline Exclusão dos outros & 1,93 & 1,53 & 2,00 & 1,47 & 1,32 & 1,00 & 0,190 \\
\hline Recusa ativa de empatia/ajuda & 0,60 & 0,86 & 0,00 & 0,25 & 0,47 & 0,00 & 0,053 \\
\hline Conflito verbal & 1,67 & 1,67 & 1,00 & 1,32 & 1,55 & 1,00 & 0,226 \\
\hline Resolução de conflito & 11,63 & 3,27 & 13,00 & 12,67 & 0,90 & 13,00 & 0,126 \\
\hline Complacência & 4,00 & 2,10 & 4,00 & 3,95 & 1,74 & 4,00 & 0,501 \\
\hline Nenhuma complacência & 2,07 & 1,31 & 2,00 & 2,05 & 1,49 & 2,00 & 0,837 \\
\hline Vergonha & 0,37 & 0,89 & 0,00 & 0,08 & 0,33 & 0,00 & 0,053 \\
\hline
\end{tabular}


Tabela 2 (continuação)

Média, Desvio Padrão e Mediana para os Itens do MSSB por Grupo

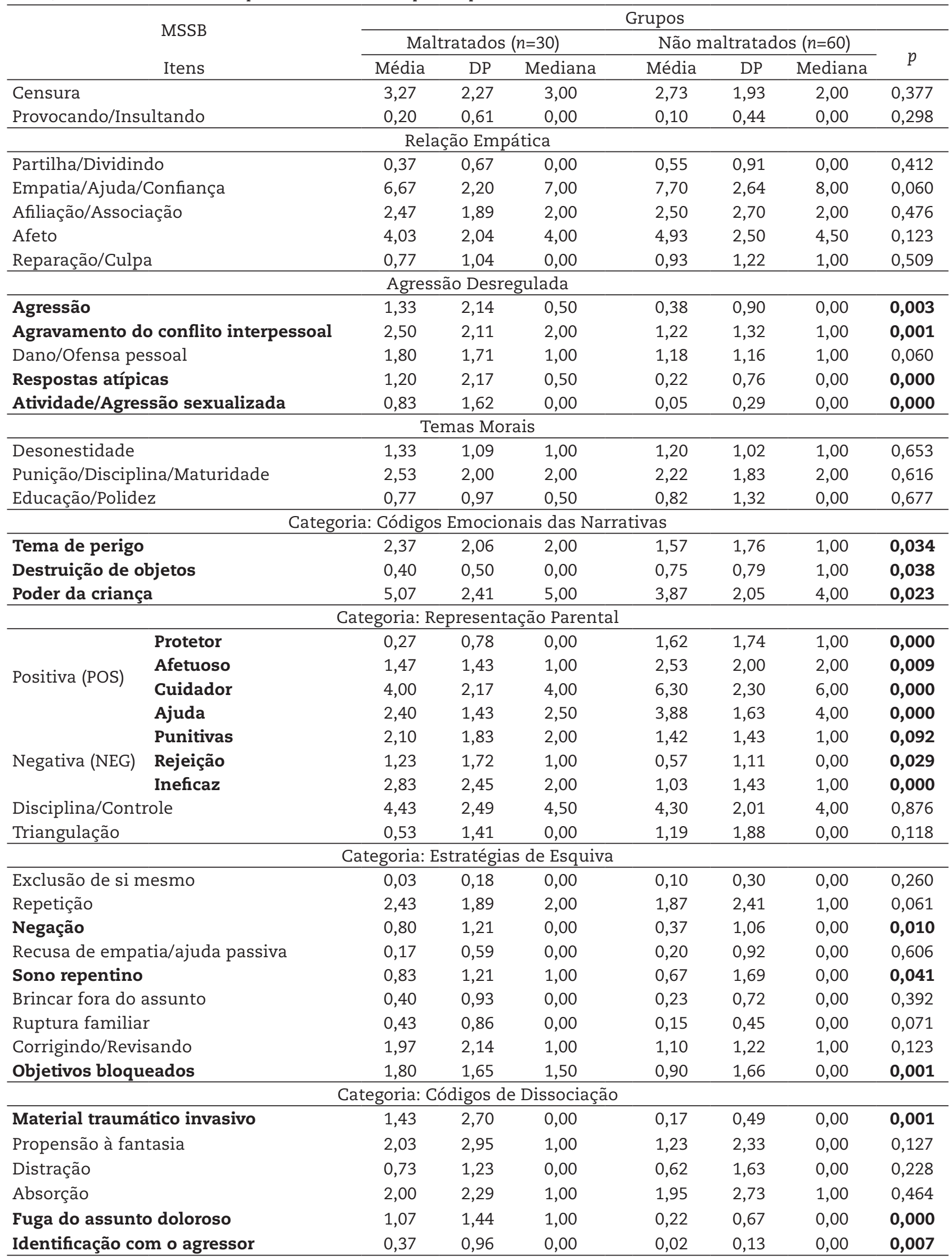

Nota. £: Teste de Mann Whitney 


\section{Discussão}

As narrativas do MSSB apresentam à criança dilemas morais ou conflitos que devem ser finalizados em uma história que envolve personagens e elementos familiares em seu cotidiano. Dessa forma, o conteúdo dos temas das histórias, os aspectos emocionais envolvidos nas situações, bem como a representação das figuras cuidadoras evocam o mundo representacional das crianças. E, além disso, a forma como o conflito é resolvido aponta para a capacidade infantil de regular as emoções, manter uma coerência narrativa ou evitar e dissociar os assuntos problemáticos.

No que se refere às representações mentais das crianças maltratadas e não maltratadas, com base nas respostas das narrativas do MSSB, foi possível observar que o grupo de crianças com presença de maus-tratos apresentou escores mais elevados no comparativo entre as médias dos escores em inúmeros itens de avaliação do instrumento. Assim, a análise temática das narrativas indiciou maior frequência de temas associados à categoria Conflito Interpessoal, que se refere a como as crianças lidam com os conflitos internos e quais recursos utilizam para dar conta de tal, entre as crianças vítimas de maus-tratos. Verificou-se que se evidenciam mais características de competição, rivalidade e ciúmes nas situações interpessoais. Demais itens foram similares entre os dois grupos, indicando que todas as crianças incluíam, nas narrativas, situações de conflitos em relação às histórias. Entretanto, a solução dessas situações de conflito indicou que a Agressão Desregulada, situações em que as crianças utilizam comportamentos desregulados de agressividade tanto entre crianças como com relação a adultos para resolução de conflito das narrativas, foi à estratégia presente entre as crianças vítimas de maus-tratos. Teores de cunho mais agressivo, agravamento de conflito, respostas atípicas e agressão sexualizada foram mais frequentes entre as crianças maltratas, indicando baixa regulação emocional e impulsividade frente a situações dilema.

Os aspectos emocionais nas narrativas avaliados por meio dos Códigos Emocionais se referem ao cunho afetivo das histórias narradas pelas crianças frente a situações conflitantes. Ficou evidente que crianças maltratadas se referiram com mais frequência a temas de perigo e poder da criança (situação em que a criança se vê obrigada a tentar resolver um problema, de forma mágica ou grandiosa, que seria responsabilidade de um adulto). A utilização desse recurso mostra que ocorre uma inversão de papéis na percepção das crianças, indicando que um personagem adulto não assume a responsabilidade das conflitivas, fazendo com que a criança desempenhe essa função. Esse tipo de representação de cuidado do adulto tem sido identificado em pesquisas sobre a representação do cuidado parental em crianças com pais com transtorno mental (Macfie \& Strimpfel, 2014) e indicam a não resposta ou a oscilação do adulto frente às demandas da criança. Nesse caso, a criança passa a exercer a função de figura cuidadora ou, nos casos de transtornos de vinculação grave, passa a não mais contar com a perspectiva de cuidado por essa figura.

Nessa direção, as representações parentais das crianças maltratadas foram mais negativas, punitivas e ineficazes. Ao contrário, as crianças não maltratadas representarem os pais como positivos e afetuosos, e assumindo um papel de cuidado e de ajuda. O estudo de Hodges et al. (2003) com crianças americanas que sofreram maus-tratos também apresentou uma alta frequência de percepção dos adultos como sendo figuras que não identificavam as necessidades ou angústias das crianças. Essas representações de vínculo estão associadas ao estilo inseguro de vinculação e, conforme Venturini, Bazon e Biasoli-Alves (2004), também há possibilidades maiores de condutas de esquiva e dificuldades em tolerar frustrações. Além disso, as autoras salientam que, nas relações entre pares, essas crianças apresentam maior agressividade e menor tolerância à frustração, o que remete às dificuldades em adquirir as "perspectivas do outro e em discriminar suas emoções para poder desenvolver um modelo de relação simétrico, baseado no sentimento de igualdade e de confiança, visto que suas experiências são caracterizadas pela exploração, submissão e violação" (Ventutini et al., 2004, p. 21).

Esses resultados corroboram com muitos estudos (Waldinger et al., 2001; Grych, Wachmuth-Schalaefer, \& Klockow, 2002; Custódio \& Cruz, 2008; Stronach et al., 2011), os quais identificaram que crianças maltratadas representam as figuras parentais como negativas e disciplinadoras nas narrativas do MSSB, notando-se que a representação negativa se associa à qualidade da interação e vinculação entre pais e filhos. Grych et al. (2002), ainda no âmbito da violência, evidenciaram crianças com menos representações positivas dos pais e mais conflitos interpessoais, bem como na pesquisa de Page e Bretherton (2003), os quais observaram que crianças com representações mais violentas dos pais tendem a desenvolver maiores problemas sociais e de comportamento do que crianças com representações positivas.

Quando as crianças utilizam algum recurso de defesa ao desenvolverem as histórias do MSSB, foram pontuados como itens característicos nas categorias de Estratégias de Esquiva e Códigos de Dissociação. Mais uma vez, neste estudo, as crianças maltratadas pontuaram mais em tal categoria, nos itens de negação, sono repentino, objetivos bloqueados, material traumático invasivo, fuga de assunto doloroso e identificação com o agressor. A presença desses elementos revela que as crianças que estão em sofrimento psíquico não conseguem suportar os temas e os sentimentos conflitantes impostos pelas narrativas, optando por utilizar recursos de fuga de assunto e de realidade. Assim, quanto mais dificuldades forem encontradas no relacionamento parental, bem como a exposição dessas crianças a fatores de risco, mais estratégias de esquiva e sinais de dissociação serão utilizadas 
pelas crianças maltratadas (Macfie, Cicchetti, \& Toth, 2001; Grych et al. 2002; Hodges et al., 2003).

Embora os resultados desta pesquisa indicaram representações mentais mais negativas associadas às experiências de maus-tratos, é importante salientar que há diferenças importantes de serem apontadas entre crianças maltratadas, visto que algumas apresentam funcionamentos distintos (internalização e externalização) e outras, inclusive, comportamentos adaptativos à sua realidade (Clyman, 2003; Cicchetti \& Rogosch, 2012; Hawkins \& Haskett, 2013). Exemplificando tal questão, no estudo desenvolvido por Hawkins e Haskett (2013), foi avaliada a formação das representações mentais com base na percepção da criança e dos seus cuidadores, bem como a presença de temas de conflito e afiliação em 74 crianças vítimas de abuso físico. A avaliação indicou dois grupos clinicamente distintos quanto às representações, sendo que $62 \%$ das crianças possuíam representações positivas e constituíam um grupo que apresentava melhor ajustamento em geral. Associado a esse grupo, um fator mediador foi identificado: a capacidade regulatória das emoções nas crianças, na qual as análises indicavam que crianças com representações positivas também apresentavam uma melhor habilidade ao manejar suas emoções. Para os autores, as implicações clínicas desses achados oferecem suporte para que o desenvolvimento de intervenções com crianças vítimas de maus-tratos seja baseado nas especificidades das representações de cada criança (Hawkins \& Haskett, 2013).

Tanto a hipótese de Regulação Emocional infantil e a Hipótese Representacional podem ser utilizadas como estratégias, principalmente entre crianças vítimas de maus-tratos, para retratar as interações com o ambiente e com os cuidadores (Oppenheim, 2003; Clyman, 2003; Sousa \& Cruz, 2010). Com base nos resultados e na literatura apresentados, observa-se que das duas hipóteses de compreensão das narrativas, a Hipótese Representacional pode ser considerada como a mais descritiva deste trabalho. Segundo Sousa e Cruz (2010), a hipótese representacional preconiza que crianças com experiências maltratantes têm a tendência em representar personagens em situações de conflito e tensão emocional, reproduzindo, nas narrativas, a dinâmica e as experiências no contexto familiar. Essas crianças tenderão a reconstruir experiências negativas e os episódios de maus-tratos de que foram vítimas (Sousa \& Cruz, 2010, p. 1602). Tal questão nos permite observar que as representações mentais impactaram na ordem da percepção do cuidado e proteção e na vulnerabilidade dessas forças no contexto infantil.
Já a hipótese da regulação emocional preconiza que as crianças modificam, ou evitam retratar, determinados comportamentos dos personagens nas suas narrativas, de modo a impedir o confronto com as emoções negativas por elas despertados (Clyman, 2003). A estratégia de regulação emocional é um processo inerentemente afetivo, que pode ser particularmente notório em crianças vítimas de maus-tratos, que se veem forçadas a lidar com o comportamento agressivo ou negligente das figuras parentais (Sousa \& Cruz, 2010; Hawkins \& Haskett, 2013).

Em síntese, a avaliação cuidadosa dos elementos conflitivos das vivências traumáticas, a forma como a criança lida com essas vivências e, principalmente, as características representacionais vinculares associadas às figuras cuidadoras são etapas fundamentais para o trabalho de vítimas de maus-tratos. Nesse sentido, o instrumento MSSB mostrou características discriminatórias válidas e, portanto, constituindo-se como uma técnica importante para o trabalho com crianças em situação de vulnerabilidade.

\section{Considerações Finais}

Os resultados deste trabalho indicam que os instrumentos narrativos são uma ferramenta útil para o acesso ao mundo interno infantil, fornecendo uma maior compreensão sobre a formação das primeiras representações desenvolvidas pelas crianças. Nessa direção, a técnica narrativa do MSSB e as categorias que pretende avaliar oferece elementos e recursos para a avaliação e posterior desenvolvimento de ações de intervenção e projetos de prevenção, auxiliando na observação e na identificação de áreas emocionais prejudicadas pelas experiências traumáticas vividas, como os casos de maus-tratos infantis.

Além disso, este estudo trouxe à tona questões relacionais entre as experiências de maus-tratos e formação de padrões representacionais que podem ser abordadas em investigações futuras, questão essa que destaca a relevância de que novos estudos nacionais sejam desenvolvidos e aprofundados nessa área, inclusive investigando comparar a constituição das representações mentais nos diferentes tipos de maus-tratos acometidos contra crianças e adolescentes.

Salientamos ainda que este estudo possui algumas limitações devido ao seu tamanho amostral e a sua coleta de dados se restringirem somente a uma região. Neste aspecto incluem-se também as questões das dimensões que o instrumento abrange e sua necessidade de capacitação para aplicação e investigação das áreas que o compõe.

\section{Referências}

Benavente, R., Justo, J., \& Veríssimo, M. (2009). Os efeitos dos maus-tratos e da negligência sobre as representações da vinculação em crianças de idade pré-escolar. Análise Psicológica, 27(1), 21-31. 
Bretherton, I., Ridgeway, D., \& Cassidy, J. (1990). Assessing internal working models of the attachment relationship: An attachment story completion task for 3-year-olds. Em M. T. Greenberg, D. Cicchetti, \& E. M. Cummings (Eds.), Attachment in the preschool years: Theory, research, and intervention (pp. 273-308). Chicago: University of Chicago Press.

Cicchetti, D., \& Rogosch, F. A. (2012). Gene x environment interaction and resilience: Effects of child maltreatment and serotonin, corticotrophin releasing hormone, dopamine, and oxytocin genes. Developmental Psychopatholgy, 2(24), 411-427. doi: 10.1017 / S0954579412000077

Custódio, S., \& Cruz, O. (2008). As representações mentais das crianças acerca das Figuras Parentais. Psicologia: Teoria e Pesquisa, 24(4), 393405. doi: 10.1590/S0102-37722008000400002

Emde R., Wolf, D., \& Oppenheim, D. (2003). Revealing the inner worlds of young children: The MacArthur Story Stem Battery and parent-child narratives. New York: Oxford University Press.

Emde, R. N. (2003). Early narratives: A window to the child's inner world. Em R. Emde, D. Wolf, \& D. Oppenheim (2003). Revealing the inner worlds of young children: The MacArthur Story Stem Battery and parent-child narratives (p.03-16). New York: Oxford University Press.

Fivush, R., Hazzard, A., Sales, J. M., Sarfati, D., \& Brown, T. (2003). Creating coherence out of chaos: Children's narratives of stressful and positive events. Journal of Applied Cognitive Psychology, 17, 1-19. doi: 10.1080/09658210802150681

Fleitlich, B., Cortazar, P. G., \& Goodman, R. (2000). Questionário de Capacidades e Dificuldades (SDQ). Revista Infanto (de Neuropsiquiatria da Infância e da Adolescência), 8, 44-50. doi: 10.1590/S0103-166X2012000400016

Grych, J. H., Wachmuth-Schalaefer, T., \& Klockow, L. L. (2002). Interparental aggression and young children's representations of family relationships. Journal of Family Psychology, 16(3), 259-272.

Hawkins, A. L., \& Haskett, M. E. (2014). Internal working models and adjustment of physically abused children: The mediating role of self-regulatory abilities. Journal of Child Psychology and Psychiatry, 55(2), 135-143. doi: 10.1111

Hodges, J., Steele, M., Hillman, S., \& Henderson, K. (2003). Mental representations and defenses in severely maltreated children: A story stem battery and rating system for clinical assessment and research applications. Em R. Emde, D. Wolf, \& D. Oppenheim. (Ed.). Revealing the inner worlds of young children: The MacArthur Story Stem Battery and Parent-child Narratives. New York: Oxford University Press, $240-267$.

Holmberg, J., Robinson, J., Corbitt-Price, J., \& Wiener, P. (2007). Using narratives to assess competencies and risks in young children: Experiences with high risk and normal populations. Infant Mental Health Journal, 28(6), 647-666. doi: 10.1002/ imhj.20158

Langevin, R., Cossette, L., \& Hebert, M. (2016). Emotion regulation in sexually abused preschoolers. Child Psychiatry \& Human Development, 47, 1-12. doi: 10.1007/ s10578-015-0538-Y

Macfie, J., \& Strimpfel, J. M. (2014). Parenting and the Development of Borderline Personality Disorder (p. 277-291). Em C. Sharp et al. (Eds.). Handbook of Borderline Personality Disorder in Children and Adolescents. ISBN 978-1-4939-0591-1, XXI. London: Springer International Publishing.

Macfie, J., Cicchetti, D., \& Toth, S. L. (2001). The development of dissociation in maltreated preschool-aged children. Development and Psychopathology, 13, 233-254. doi: 10.1017/S0954579401002036

Mendes, T. C., \& Sani, A. (2015). Representações de crianças expostas à violência interparental através de provas projetivas. Revista de Psicologia da Criança e Adolescente, 6(1), 171-192.

Mesquita, P. C., \& Benetti, S. P. C. (2014). A representação materna de crianças com mães depressivas. Arquivos Brasileiros de Psicologia, 66(2), 53-67.

Oppenheim, R. Emde, R. N., \& Warren, S. (1997). Children's Narrative representation of mothers: Their development and associations with child and mother adaption. Child Development, 68(1), 127-138.

Page, T., \& Bretherton, I. (2003). Gender differences in stories of violence and caring by preschool children in post-divorce families: Implications for social competence. Child and Adolescent Social Work Journal, 20, 485-508. doi: 10.1023/B:CASW.0000003140.44020.ba

Pasquali, L. (2003). Psicometria: Teoria dos testes na psicologia e na educação. Rio de Janeiro: Vozes.

Priel, B., Besser, A., Waniel, A., Yonas-Segal, M., \& Kuperminc, G. (2007). Interpersonal and intrapersonal processes in the formation of maternal representations in middle childhood: Review. New findings and future directions. Israel Journal Psychiatry \& Related Sciences, 44(4), $255-265$.

Robinson, J. L., Mantz-Simmons, L., MacFie, J., Kelsay, K., \& Homberg, J. (2007). MacArthur Narrative Coding Manual. MacArthur Narrative Working Group.

Sampieri, R. H., Collado, C. F., \& Lucio, M. P. B. (2013). Metodologia de Pesquisa. 5. ed. Porto Alegre: Penso.

Sousa, M. L., \& Cruz, O. (2010). As narrativas das crianças institucionalizadas: A experiência dos maus-tratos e a construção dos modelos representacionais. Actas do VII Simpósio Nacional de Investigação em Psicologia, Universidade do Minho, Portugal, 1600-1614.

Stronach, E. P., Toth, S. L., Rogosch, F., Oshiri, A., Manly, J. T., \& Cicchetti, D. (2011). Child maltreatment, attachment security and internal representations of mother and mother-child relationships. Child Maltreatment, 16(2), 137-145. doi: 10.1177/1077559511398294.

Toth, S. L., Cicchetti, D., Macfie, J., Maughan, A., \& VanMeenen, K. (2000). Narrative representations of caregivers and self in maltreated preschoolers. Attachment \& Human Development, 2(3), 271-305. doi: 10.1080/14616730010000849

Venturini, F. P., Bazon, M. R., \& Biasoli-Alves, Z. M. M. (2004). Família e violência na ótica de crianças e adolescentes vitimizados. Estudos e Pesquisas em Psicologia, 1, 20-33.

Waldinger, R. J., Toth, S. L., \& Gerber, A. (2001). Maltreatment and internal representations of relationships: Core relationships themes in the narratives of abuse and neglected preschoolers. Social Development, 10(1), 41-58.

recebido em setembro de 2016 aprovado em setembro de 2017

\section{Sobre as autoras}

Joana Alvares é graduada em Psicologia pela Universidade do Vale do Rio dos Sinos - UNISINOS, São Leopoldo - RS, e Mestre em Psicologia Clínica pela mesma instituição. Cursa Formação em Psicoterapia Psicanalítica no Instituto de Ensino e Pesquisa em Psicoterapia IEPP / Serra Gaúcha.

Letícia Fagundes Machado é graduanda em Psicologia pela Universidade do Vale do Rio dos Sinos - UNISINOS, São Leopoldo - RS e bolsista UNIBIC de Iniciação Cientifica, no Programa de Pós Graduação em Psicologia (PPG) pela mesma instituição sob orientação da Professora Silvia P. C. Benetti.

Sílvia Pereira da Cruz Benetti é Doutora em Estudos da Criança e da Família, Syracuse University, USA. Professora do Programa de Pós-Graduação em Psicologia da Universidade do Vale do Rio dos Sinos - UNIINOS, São Leopoldo - RS. 